\title{
The Buenos Aires Affair: el comienzo de la obra por venir
}

\section{The Buenos Aires Affair: the beginning of the work to come}

Juan Pablo Canala

sanchocuarto@yahoo.com

Universidad Nacional de Buenos Aires, Programa de Historia Social y Económica, Instituto de Historia Argentina y Americana "Dr. Emilio Ravignani" (UBACONICET), Argentina

Cita sugerida: Canala, J. P. (2020). The Buenos Aires Affa ir: the beginning of the work to come. Orbis Tertius, 25(32), e173. https://doi.org/10.24215/18517811e173

\begin{abstract}
Resumen: El presente trabajo intentará demostrar que una atención demorada de las diversas instancias redaccionales de The Buenos Aires Affair de Manuel Puig permite comprender que es en esta novela donde se produce un viraje en el proyecto literario del autor. A partir del análisis del uso del diálogo, del fluir de la voz narrativa, como así también el empleo de las notas al pie, se analizará el proceso escritural de la novela, donde los manuscritos conservados en el archivo por el escritor se constituyen como el semillero, como el espacio en el que confluyen una serie de intereses, de motivos, de imágenes, de técnicas y procedimientos que encontrarán su desarrollo en las novelas siguientes, constituyendo a esta novela como un nuevo comienzo de su literatura.
\end{abstract}

Palabras clave: Manuel Puig, Crítica Genética, Voz, Sexualidad, Aborto.

\begin{abstract}
The present work will try to show that a delayed attention of the diverse editorial instances of Manuel Puig's The Buenos Aires Affair allows us to understand that it is in this novel where a turn occurs in the author's literary project. From the analysis of the use of dialogue, the flow of the narrative voice, as well as the use of footnotes, the novel's writing process will be analyzed, where the manuscripts kept in the archive by the writer are constituted as the seedbed, as the space in which a series of interests, motifs, images, techniques and procedures converge that will find their development in the following novels, constituting this novel as a new beginning of his literature.
\end{abstract}

Keywords: Manuel Puig, Genetic Criticism, Voice, Sexuality, Abortion.

\section{I. ¿EPÍlOGo o PRólOgo?*}

El 4 de julio 1973, Manuel Puig recibió una carta proveniente de la ciudad bonaerense de Mar del Plata. La misiva en cuestión se encontraba firmada por "una lectora", como si la persona que la escribiese definiera, sin eufemismos, un rol muy concreto a la hora del intercambio que iniciaba con su envío. En ella, Alba (ese era su nombre), le comunicaba al escritor:

Hace escasamente media hora que terminé de leer su tercera novela: The Buenos Aires Affair, considerándome afortunada al conseguir el último ejemplar, cuando en los demás lugares estaba agotado. Ahora no sé si estoy disgustada con Ud. por haber escrito semejante porquería. ${ }^{1}$ 
El registro de la lectora, un tanto exasperado, surge del impulso irrefrenable e inmediato de plasmar, por medio de la escritura, la incomodidad y la frustración experimentadas frente sus propias expectativas sobre la novela. Dirá más adelante: "Su Boquitas me gustó tanto que tuve el deseo de viajar a Villegas para conocer ese pueblo y su gente (...) pero esta última novela me ha dejado perpleja”. Será esa perplejidad la que se expandirá en el cuerpo mismo de la carta, donde Alba irá desplegando sus impresiones de lectura: "muy ingenioso hacer trabajar la mente del lector haciendo que imagine la parte del diálogo que falta, pero si además tiene que descifrar una versión taquigráfica (...) termina por fastidiarse" y, finalmente: "uno termina asqueado de tanto sexo".

Las impugnaciones de esta lectora, tanto temáticas como formales, surgidas de la más absoluta decepción, nos lleva a interrogarnos: ¿Por qué Puig se alejaba del exitoso modelo que había creado en sus dos primeras novelas? ¿Por qué optaba por desviarse de aquello que sus lectores estaban esperando que escribiera? Las impresiones de Alba no fueron muy diferentes de aquellas que cierto sector de la crítica desarrolló en torno a la tercera novela de Puig. En el ámbito local, muchos de los textos escritos en ocasión de la publicación del libro esgrimieron argumentos similares. La tendencia de leer invariablemente a esta novela en serie con las anteriores, lejos de señalar los hallazgos innovadores del texto, redundaron en juicios adversos: "Resulta una decepción y un aburrimiento (...) El recorrido está trillado y trillado sin distancia crítica" decía una reseña de la revista porteña Siempre, concluyendo: "The Buenos Aires Affair me sobra." (Aguilar Mora, 1973, p. 5). Esta opinión se replicó en muchos comentarios presentes, tanto en la prensa masiva como en las revistas literarias, donde de forma unánime se resaltaron los supuestos defectos del libro. ${ }^{2}$ En aquel entonces muchos pensaron, al igual que la reseña antes mencionada, que The Buenos Aires Affair sobraba en la obra de Puig. Si la adversa recepción contemporánea sostenía su argumentación refutando tanto los procedimientos formales como el contenido sexual y político de la novela, su posterior censura por parte del gobierno peronista y el exilio mismo del escritor, terminaron de malograr el destino del libro (Jill-Levine, 2002; Martinetto, 2016).

En las diversas reflexiones críticas que pretendieron periodizar la obra de Puig ${ }^{3}$ esta novela constituyó una suerte de eslabón perdido, un texto inclasificable, un libro extraño e incómodamente leído, jaqueado entre los dos grandes éxitos editoriales del escritor. La fortuna crítica de The Buenos Aires Affair se circunscribió a los numerosos trabajos dedicados a leer sus vínculos con el policial, ${ }^{4}$ obturando la posibilidad de una lectura integral de la novela. La renovación crítica a comienzos de este siglo interrogó al corpus puiguiano a partir de nuevos instrumentos teóricos. En esa línea Alberto Giordano, en su ya clásico libro, señaló que con The Buenos Aires Affair, Puig había abandonado la narración de voces triviales en conversación, optando por una "estrategia de autoreflexividad" (2001, p. 26) que dominaba la composición de su novela. En su lectura, el crítico planteaba continuidades entre la práctica artística de Puig y de su protagonista, Gladys Hebe D'Onofrio. De este modo, postulaba que el retorno a la conversación y el despojamiento técnico presentes en su novela siguiente, El beso de la mujer araña (1976) indicaba que allí se: "anuncia la necesidad de recomenzar" (Giordano, 2001, p. 28). La lectura de Giordano aísla la potencialidad de The Buenos Aires Affair, al entenderla como un "parteaguas" entre dos momentos dentro de la obra de Puig. Ahora bien, qué ocurriría si consideráramos a la escritura de esta tercera novela, no como un desvío de la poética del escritor, en tanto clausura de un primer ciclo, sino como el ámbito que hizo posible la obra por venir. En este sentido, fue José Amícola el primero en reparar en su centralidad: "The Buenos Aires Affair fue una novela pensada como un punto nodal en su producción y es lícito, entonces, considerarla un verdadero campo de batalla” (2000, p. 134).

Resulta instigadora la caracterización que Amícola hace de la novela y la elección de la metáfora bélica, que sintetiza ajustadamente el intenso proceso de escritura llevado adelante por Puig. Para interrogar las tensiones originarias que confluyeron en el desarrollo de esta novela, entendiéndolas como la oportunidad de un nuevo comienzo, resulta indispensable inscribirnos en la perspectiva de la crítica genética, en tanto que supone abrir el texto a su proceso de génesis, esto es, a entenderlo como una escritura viva, tal como la definió Louis Hay, que busque "desentrañar las redes de sentido de un manuscrito particular" (1994, p. 16). Asimismo, como 
ha señalado Graciela Goldchluk: "El manuscrito no es la preparación del texto; no es lo mismo, pero sin terminar, sino que es otro (...) lo que se incorpora no son únicamente manuscritos, sino una constelación documental cuya forma es la del archivo. Leer a partir del archivo implica, de ese modo, romper la linealidad y atender a relaciones múltiples" (2016, p. 60-61). La posibilidad de la lectura que habilita el archivo, no solo permite dar cuenta de las diferentes vacilaciones alrededor del proceso de escritura de una novela particular, sino que abre un espacio, donde se alojan formas germinales o, como ha planteado Roland Barthes, donde acontece el "acto mínimo de enunciación”, la "forma ultra breve", el "átomo de frase” (2005, p. 59). En este sentido, los manuscritos conservados en el archivo se constituyen como el semillero, como el espacio en el que confluyen una serie de intereses, de motivos, de imágenes, de técnicas y procedimientos que encontrarán su desarrollo en las novelas siguientes.

Desde esta perspectiva, entonces, postulamos que el largo proceso escritural de The Buenos Aires Affair introduce en la narrativa de Puig una marca decisiva al incorporar procedimientos y discursos ausentes en sus dos primeras novelas, constituyéndose, así como el momento inicial de una constante de intereses rastreables en los libros que abarcan el período 1973-1980. La hipótesis que articula este trabajo intentará demostrar que una atención demorada de las diversas instancias redaccionales de esta tercera novela permite, gracias a la lectura de los sucesivos estadios redaccionales y en diálogo con los apuntes meta escriturarios llamados pre-redaccionales, comprender que es en la escritura de ese libro donde se produce un viraje en el proyecto literario de Puig y que será en las huellas materiales que deja en el "campo de batalla" de la escritura, donde el autor presentará sus principales innovaciones técnicas (el uso del diálogo, el fluir de la voz y el uso de las notas al pie) e incorporará nuevos discursos como la política, el psicoanálisis y la sexualidad, estableciéndose aquí un nuevo comienzo para su literatura.

\section{Tecnologías de LA PALABRA}

En un curriculum laboral fechado hacia 1959, Manuel Puig, ávido de conseguir un empleo, reconstruía su experiencia previa. En esos aos había garantizado su subsistencia, gracias a sus conocimientos del mundo del cine, como asistente de diálogos, o bien por su destreza para los idiomas en alguna oficina de importación. Ambas herramientas le garantizaron un medio de vida mientras seguía trabajando en lo que sería su primera novela. De la enumeración de su experiencia laboral presente en este documento, resulta interesante sealar un empleo concreto en el que confluyen ambas habilidades, y que tiene al diálogo como centro: "I wrote the Spanish sub-titled version of several Italian films". (Curriculum Vitae, ID puig.DDcs.D.A.11.0002). ${ }^{5}$ La tarea, en apariencia mecánica, de subtitular películas supone, por un lado, la comprensión de los límites formales y estructurales de un guion, y por el otro, la habilidad de trasladar la voz del filme, enunciada en una lengua determinada a su puesta por escrito. Este procedimiento implica, por parte de quien subtitula, no solo el proceso de traducción que supone el pasaje de una lengua a otra, sino también una adecuada selección de las palabras que capten por escrito los tonos y los climas de las diferentes escenas de una película. La encrucijada técnica que implica la tarea de subtitular películas puede ser interpretada como un privilegiado ámbito de entrenamiento para reflexionar acerca del trabajo con el diálogo, entendido como forma narrativa. De esta manera, retomar este formulario burocrático permite indagar acerca de los modos en que la escritura de Puig trabajó con la mediación tecnológica que implica, tanto el registro escrito de la voz, como el proceso de traducción del discurso. En ese sentido, en la literatura de Puig no se trata de la escucha del diálogo, como en la voz captada por el cine, sino, como afirma Delfina Cabrera de "una conversación a partir de la lectura de una forma escrita" (2016, p. 152). La continuidad entre estas prácticas aprendidas tempranamente (como guionista y subtitulador) y la reflexión acerca del uso del diálogo y de la conversación como sustancia primordial de la narración, perviven en los procedimientos de escritura presentes en las primeras redacciones de The Buenos Aires Affair de manera mucho más acentuada que en sus dos novelas anteriores. El consenso más o menos establecido sostiene que Puig "no necesitó recurrir en El beso de la mujer araa más que al 
diálogo" (Giordano, 2001, p. 27) estableciéndose allí un punto de inflexión dentro de su obra. La evidencia material del proyecto narrativo que el escritor lleva adelante en las diferentes fases redaccionales de The Buenos Aires Affair permite, al menos, matizar esa afirmación. En las sucesivas formulaciones de cada uno de los capítulos se advierte una presencia decisiva del diálogo como procedimiento central en la escritura de su tercera novela. De esta manera, atender al proceso escritural del libro permite advertir la experimentación formal mediante una narración fundada inicialmente en la voz y en el diálogo.

Si se atiende a la arquitectura que tenía la novela en las primeras versiones redaccionales, se puede advertir que la presencia del diálogo ocupaba un gran número de capítulos. De los 16 que conformar el libro, en las primeras versiones manuscritas, 8 de ellos respondían al esquema del diálogo desarrollado. De esa formulación inicial, los únicos capítulos que no alteraron su forma en la versión publicada fueron: el capítulo 7 (la entrevista imaginada por Gladys) y el 12 (la conversación entre Leo y el policía). Existen otros casos donde esos diálogos fueron desechados por completo, por ejemplo, el capítulo 1, en cuya primera versión, Clara Evelia dialogaba con un oficial de policía acerca de la desaparición de su hija, o el capítulo 14 donde Leo le narraba a su psicoanalista el encuentro de Gladys con María Ester Vila (MEV) en su departamento. En este sentido, en las sucesivas reescrituras, Puig renunció a esa forma dialogada inicial, imponiéndoles a estos capítulos una estructura narrativa en la que apeló a otras resoluciones formales que complejizaron el uso de la voz y el juego con el punto de vista. Por último, en los capítulos 5, 8, 9 y 10, el despliegue de la forma dialogal aparece intervenido por diversas estrategias, ya sea por medio de la omisión de uno de los interlocutores, o bien por la reescritura mediada por diversas tecnologías.

En ese punto habría que establecer algunas diferencias respecto de las novelas anteriores. Si bien en $L a$ traición de Rita Hayworth (1968) y en Boquitas pintadas (1969) también aparece el diálogo mediado por alguna de estas técnicas antes señaladas, si se atiende el punto de vista de la génesis textual, la concepción de escritura llevada adelante por Puig resulta divergente. En la primera novela, la ausencia de uno de los interlocutores como recurso técnico aparece en el capítulo 4: "Diálogo de Choli con Mita, 1941". La lectura de la versión publicada solo deja leer las intervenciones de Choli, delegando en el lector la reconstrucción imaginaria de las eventuales declaraciones de su interlocutora. Si se atiende a las diferentes instancias redaccionales de este capítulo, en la primera versión, Puig había desarrollado un monólogo (la forma narrativa predominante en los borradores de esta novela) al que, en un índice preliminar, tituló como: "IV. La amiga de la madre". A partir de la versión redaccional siguiente, Puig va interviniendo ese monólogo (eliminando frases y segmentando el discurso), para armar los parlamentos que, a partir de la versión siguiente, abandonan su formulación inicial, para presentarse como un diálogo construido por un solo interlocutor. ${ }^{6}$ El segundo ejemplo que nos gustaría señalar, se refiere al modo en el que aparece la confesión de Mabel en la "Decimocuarta entrega" de Boquitas pintadas. Puig presenta los dichos del personaje ante la autoridad de un cura, mediante la ausencia del interlocutor y mostrando, incluso gráficamente, los espacios escandidos que marcan el silencio y la alternancia en los turnos de la conversación. Sin embargo, en las diversas fases redaccionales, se advierte que Puig concibió este capítulo solo con las intervenciones de Mabel, a las que fue reescribiendo profusamente (Rodas, 2015, pp. 232-236).

De este modo, el diálogo aludido en La tradición de Rita Hayworth en apariencia no difiere de cualquiera de los capítulos de The Buenos Aires Affair que presentan conversaciones, en las que uno de sus interlocutores se encuentra ausente (aquellas mantenidas entre Leo y MEV, o entre MEV y el oficial). Del mismo modo, en el segundo caso, la confesión de Mabel aparece formalmente de la misma manera que las divagaciones de Leo en el médico, presentes en el capítulo 8 (la ausencia del interlocutor, el desarrollo de la narración del personaje y la presencia de los silencios). El efecto de continuidad en el uso de esos procedimientos lo da la lectura conjunta de las versiones publicadas de las tres primeras novelas de Puig. No obstante, si se atiende al proceso escritural de ellas, lo que puede señalarse es que en The Buenos Aires Affair la génesis de la conversación, a diferencia de las novelas anteriores, se presentaba bajo la forma desarrollada del diálogo, que luego era intervenido a partir de diferentes mediaciones técnicas. Lo que marca esta distancia en la escritura es que, en su tercera 
novela, el diálogo no es producto de un efecto técnico, sino es la sustancia misma de la narración, sobre la que luego operarán intervenciones que modelarán las diferentes conversaciones mantenidas por los personajes. Mientras que en las dos primeras novelas se trata de un monólogo escandido por silencios, en The Buenos Aires Affair se parte de un diálogo real que, en el borramiento de uno de los interlocutores, inscribe las huellas de lo ausente en la sección del diálogo que el lector conoce.

Asimismo, otro elemento que permite señalar la singularidad de la tercera novela respecto de las anteriores se relaciona tanto con el contenido como con los discursos que son incorporados a la narración. No se trata ya de voces de pueblo o voces que solo tenían, como dijo repetidas veces Puig, "banalidades para contar" (Puig 1985: 10), sino por el contrario, las voces que irrumpen en las versiones dialogadas de The Buenos Aires Affair, no tienen nada de banal. El uso del diálogo en esos borradores se constituye como el espacio privilegiado para que en la novela se incorporen discursos sobre la sexualidad, la política y el psicoanálisis. Ahora bien, lo que muestran estos escritos es cómo Puig, que se había alejado de los guiones expandiendo un monólogo hasta que se convirtió en novela, sale de la trampa de una fórmula esperada regresando al diálogo como procedimiento dominante en la génesis de su texto y a la vez ejerce, con posterioridad, fuertes reescrituras que atenuaron la centralidad de este rasgo. Los borradores iniciales del libro que pretendía escribir presentaban continuidades con la forma de los guiones que ya había escrito o de los subtítulos de película que había ensayado años antes. En ese sentido, la innovación que operó sobre las diversas formas en las Puig reelaboró esa forma dialogada inicial, se vincula con la reflexión teórica misma alrededor de la narración, que irrumpe en una temporalidad posterior a las primeras versiones desarrolladas de su futuro libro. Existe una tensión entre esos dos momentos diferenciados que se deja traslucir en dos pre-redaccionales de la novela, cuyas reflexiones meta-escriturarias, fueron producidas con posterioridad a las primeras versiones del libro, y que problematizan la escritura de la novela desde un punto de vista teórico. Veamos la primera nota:

Figura 1

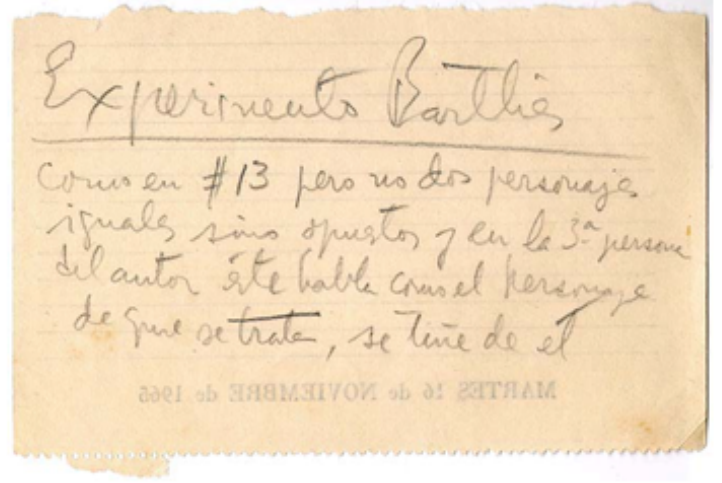

\section{Experimento Barthes Como en \# 13 pero no dos personajes iguales sino opuestos y en la 3ra persona del autor éste habla como el personaje de que se trata, se tiñe de él}

(TBAA, ID puig.NTbaa.N.C.10.0085R)

El apunte alusivo a Roland Barthes es posible que refiera a algunas de las aproximaciones teóricas que el crítico francés desarrolló en su "Introducción al análisis estructural del relato" (1966). ${ }^{7}$ La reflexión que introduce aquí Puig también supone un alcance mayor que la de la mera indicación de los instrumentos técnicos destinados a analizar los textos desde una perspectiva, todavía entonces, estructuralista. No obstante, una lectura demorada del ensayo en cuestión permite profundizar el alcance de esta referencia de lectura. Si se atiende a la definición misma que Barthes despliega alrededor del concepto de "relato", para ejemplificar, enumera aquellos materiales que pueden ser considerados dentro de esta categoría: "El relato puede ser soportado por el lenguaje articulado, oral o escrito, por la imagen, fija o móvil, por el gesto y por la combinación ordenada de todas estas sustancias (...) el cine, las tiras cómicas, las noticias policiales, la conversación" (Barthes 1988, p. 65). La enumeración de Barthes que hemos citado podría constituir un catálogo de todas las formas del relato que Puig incorporó a la trama narrativa de The Buenos Aires Affair. 
La presencia del cine (bajo la forma de la cita presente en los epígrafes de la novela), la alusión a las tiras cómicas de Rico Tipo (particularmente en la descripción de las exuberantes mujeres de las caricaturas de Divito), como así también, el modo en el que la ficción incorpora a la trama de la novela fragmentos de textos periodísticos (tanto los cables de noticias, como de crónicas policiales) incluidas en las escenas del oficial. En la cita, Barthes incorpora en último lugar a la conversación como una más de las sustancias que articulan el relato. En ese sentido, la exposición teórica del crítico francés, cifrada a partir de la alusión presente en el apunte de "Experimento Barthes", adquiere resonancias mayores. Aunque la expresión titula un señalamiento específico acerca del uso técnico del juego narrativo, también supone una afirmación acerca de la experimentación que abre esta novela en la obra de Puig, sostenida en la propia caracterización que Barthes desarrolla en su ensayo y que convierte a The Buenos Aires Affair una novela conceptualmente barthesiana. Puig, que para ese entonces había fundado su mito de origen en el paso del guion a la novela. en este nuevo comienzo de su obra y Barthes mediante, se rehúsa a que el guion vuelva a entrar en la novela. ${ }^{8}$

En el segundo apunte, Puig reflexiona sobre la incorporación de ciertos procedimientos que vienen del teatro.

Figura 2 [Detalle]
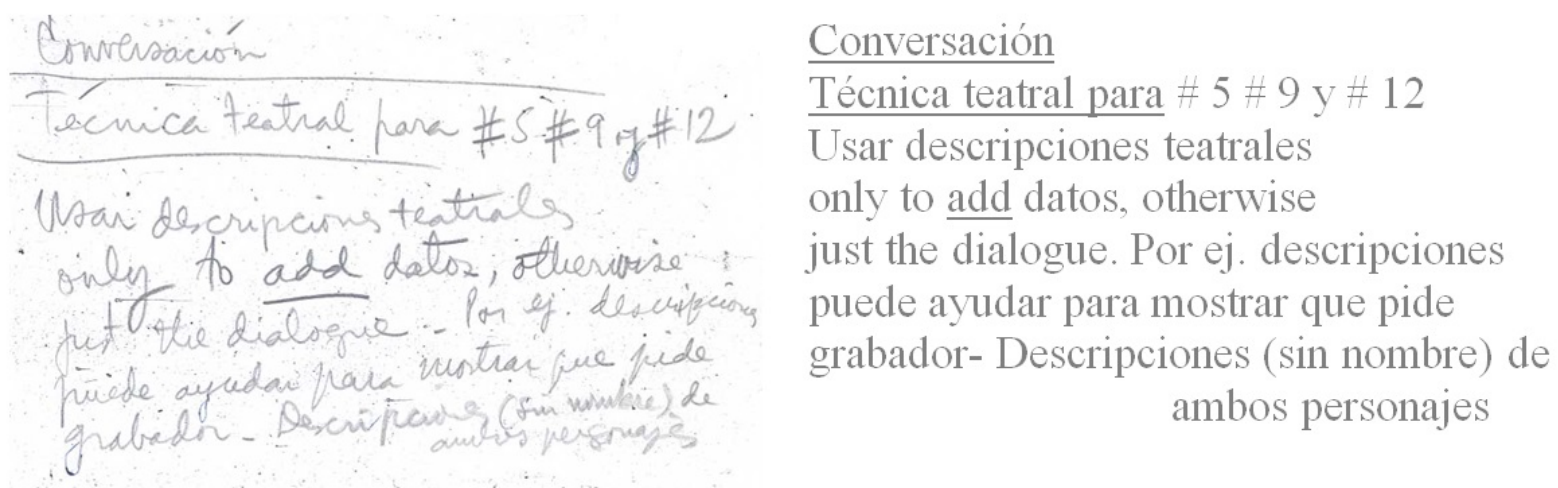

(TBAA, ID puig.NTbaa.N.C.11.0130R)

El uso de la descripción teatral (o didascalia) resulta un procedimiento que Puig decide incorporar en los tres capítulos en los que se entabla un diálogo con la autoridad policial (las dos conversaciones telefónicas de MEV y la declaración tomada a Leo). En ese contexto es donde se prevé la incorporación paulatina, en las diferentes fases redaccionales, de las acotaciones que contextualizan el espacio y que despliegan, la presencia de diferentes tecnologías en el registro de la conversación de los personajes. Puig relee las primeras versiones de su novela y reflexiona sobre las nuevas técnicas a emplear en una instancia posterior. Esto permite advertir las diferentes estrategias con las que Puig, por medio de la experimentación con las formas narrativas vinculadas al diálogo, eludió las formas del guion o del texto teatral, complejizando la escritura de los diferentes capítulos.

Una cuestión destacable es que los capítulos dialogados se inscriben en dos escenas típicas y opuestas entre sí. Por un lado, la de la conversación íntima donde los personajes refieren a sus miedos, sentimientos y experiencias desplegando diversos aspectos de su subjetividad. Por el otro, las escenas en las que la conversación es presentada en el ámbito público y frente a una autoridad del estado. Estos mismos esquemas se repiten en las tres novelas siguientes. Los diálogos entre Molina y Valentín, entre Ana y Pozzi o entre Larry y Ramírez, se constituyen como el ámbito para el desarrollo de reflexiones sobre sexualidad y política, presentes en El beso de la mujer araña (1976), Pubis angelical (1979) y Maldición eterna a quien lea estas páginas (1980). Del mismo modo acontece, en los debates en torno a cuestiones fundadas en aspectos del psicoanálisis, como discusión entre Ana y Pozzi sobre Lacan, o en las referencias al complejo de Edipo comentadas por Ramírez y Larry. Si en la tercera novela, los intercambios entre Leo y MEV con la policía suponían una instancia 
dialogal atravesada por la tutela del control que supone toda declaración ante la autoridad estatal, en la novela siguiente, Puig retoma ese esquema en los capítulos en los que Molina conversa con el director de la cárcel.

En The Buenos Aires Affair, la voz es una materia maleable, es un recurso verbal que la narrativa de Puig interviene bajo diferentes formas y tecnologías que moldean y modelan la captura literaria de aquello, que, en sus libros, dicen los personajes. Tomando al diálogo como cosmos inicial, como sustancia primordial de la narración, Puig reescribe alterando el punto de vista, experimentando con las posibilidades técnicas (la mediación de la máquina $)^{9}$ o, como se verá en el apartado siguiente, con el uso de la nota al pie para producir allí un vacío y para complejizar la percepción de los hechos y de los personajes. Estas estrategias apelan a la emergencia de un lector más activo y atento a los acontecimientos, que, a diferencia de las primeras versiones, se encuentran atenuados y escondidos bajo diferentes técnicas narrativas.

\section{LA SEXUALIDAD, UNA NOTA AL PIE}

La irrupción de la nota al pie en la escritura de The Buenos Aires Affair, en tanto recurso narrativo de orden paratextual, introduce una innovación respecto de las novelas anteriores, a la vez que anticipa su uso en la novela siguiente; sin embargo, resulta sintomático que la crítica, que casi de forma unánime no puede prescindir del análisis de las notas al hablar de El beso de la mujer araa, pase por alto las de la novela anterior. La nota al pie establece una de las estrategias centrales para pensar el modo en el que las ficciones de Puig recortan, de forma concreta, un espacio material que se vuelve el ámbito privilegiado para desplegar aproximaciones y discursividades en torno a la sexualidad. Como sostiene Anthony Grafton, las notas al pie "constituyen una narración secundaria que sigue la trama primaria, pero difiere nítidamente de ella. Al documentar el pensamiento y la investigación que sustentan la narración en la cabeza de página” (1998, p. 23). Por su parte, fue Shary Benstock quien, en un pionero trabajo sobre la narrativa inglesa, analizó los usos de la nota al pie en el ámbito de la literatura. Desde su perspectiva, la economía formal de este paratexto, a pesar de su aparente sencillez, comporta una significación adicional de mayor alcance: "By definition, footnotes are physically more constrained than the primary text: they are minimal, skeletal, succinct, their purpose being to elaborate on the text without engulfing it; at the same time, they are freer to adopt a new line of rhetoric" (1983, p. 204). Resulta interesante retomar aquí ambos planteos críticos, entendiendo a la nota al pie, tanto como la posibilidad de introducir en el texto una linea retorica diferente, que redefina su significación y trasgreda las expectativas que la convención le marca al lector, como así también la de constituirse como una narración segunda que, lejos de sustentar lo que se predica en el texto principal, establece otros diálogos posibles con él, incorporando una voz narrativa que pugna por el sentido de la obra. Si bien el recurso tiene en la literatura argentina una vasta tradición que precede al propio Puig ${ }^{10}$, su incorporación a The Buenos Aires Affair supone, a efectos de la construcción de la trama, un significado particular que solo puede comprenderse cabalmente a partir de un análisis cuidadoso del proceso escritural de la novela.

En los profusos manuscritos conservados de la obra se advierten tensiones alrededor de la emergencia y de la funcionalidad de la nota al pie dentro de la trama narrativa. Si se atiende a los borradores iniciales de la primera fase redaccional de los capítulos 4 y 9, Puig inserta allí una serie de notas que, como se verá, versarán sobre diferentes aspectos de la sexualidad de Gladys y MEV. De ambos grupos de notas se desprende un común denominador en el que se advierte que la representación de la sexualidad femenina prescinde de la tutela masculina omnipresente encarnada por Leo y fundada en la sumisión, el dolor y la violencia que domina los vínculos sexuales a lo largo del decurso narrativo. De modo que lo que allí se aloja, marcaría una suerte de sexualidad otra en el texto, donde la masturbación y el aborto, tematizados en las notas al pie, constituirían una alternativa concreta al sometimiento sexual que recorre la novela.

En los manuscritos que conforman los pre-redaccionales existentes de la obra, hay algunos bosquejos, como se verá, que permiten dar cuenta que Puig reflexionó previamente sobre la eventual posibilidad de incluir 
notas al pie. No obstante, no hay en los borradores alusión alguna que remita ni a masturbación femenina, ni al aborto como temas a incorporar al plan general de la novela. De modo que, aunque se adviertan divergencias en el proceso escritural de los capítulos en cuestión, de acuerdo con la evidencia material, la incorporación de sexualidad femenina a las notas se produce en la fase redaccional, esto es, en el momento mismo en el que autor está realizando la puesta por escrito de los capítulos en cuestión.

Si nos centramos en las notas al pie del capítulo 4, donde Gladys llevada por el fluir de la conciencia y de la imaginación, satisface ella misma su deseo sexual, debe advertirse que estos paratextos no se encuentran en las dos primeras versiones redaccionales de la novela. Por el contrario, irrumpen a partir de la versión tercera del capítulo, donde Puig las incorpora en forma manuscrita. A partir de la versión siguiente, las notas, ya pasadas a máquina, se formalizan y son incorporadas al texto. En este punto, resulta significativo que entre la versión manuscrita primigenia y la primera edición publicada no se registren reescrituras sustanciales. Puig no reformula la masturbación de Gladys, como si en la génesis misma de esos fragmentos, hubiera captado el efecto concreto de aquello que pretendía trasmitir y que no requirió mayores cambios. La ausencia de vacilación en la escritura de esas notas supone también la voluntad deliberada de hacer visible la exploración de ese cuerpo sexuado, donde la narración presente al pie irrumpe como una voz que reclama en la novela la aparición de una sexualidad desprovista del dolor y del dominio que impone la tutela masculina sobre el cuerpo de las mujeres. Asimismo, el hecho de que la autosatisfacción de Gladys se aloje en una nota al pie, no constituye a esa masturbación como una versión marginal, degradada o paródica respecto de otras formas de la sexualidad presentes en los diferentes capítulos del cuerpo del texto. Por el contrario, en la masturbación se advierte un cierto resguardo de ese cuerpo femenino respecto de la violencia que domina los actos sexuales presentes en el texto principal. No obstante, en el contenido de esas notas, se advierte la descripción de anatomías y sensaciones que, estimuladas por la voluntad de Gladys, también reclaman la presencia fragmentaria e imaginaria de las experiencias sexuales pasadas. Al seleccionar del repertorio de sus recuerdos, tomados ellos de los episodios biográficos que la novela desarrolló en el capítulo anterior, las notas en cuestión despliegan una serie de acciones tendientes a evocar un conjunto reducido de encuentros sexuales pasados. Así, del total de las notas incluidas, tan solo tres de ellas recuperan la presencia del sujeto masculino: "trata de visualizar el sexo erecto del modelo, sin lograrlo" (Puig, 1973, p. 67); "presiona su uña contra la piel, como lo hizo Bob antes de poseerla" (Puig, 1973, p. 71); "logra recordar con exactitud la sensación producida por el pene voluminoso de Frank" (Puig, 1973, p. 75). El mosaico construido alrededor del recuerdo de los tres hombres, marca una temporalidad donde la evocación imaginaria de esas circunstancias eróticas vividas por Gladys, construyen un relato acerca de aprendizaje en torno al placer. En la primera nota, se evoca el temprano encuentro con la anatomía masculina a través del modelo vivo de la academia de arte: "un órgano sexual de dimensiones fuera de lo común" (Puig, 1973, p. 39) que Gladys contrasta con su propia idea inicial al respecto: "el pene pequeño como las estatuas griegas" (Puig, 1973, p. 39). En la segunda nota en cuestión, se evoca la exploración de la propia genitalidad femenina por medio de los juegos sexuales practicados por Bob: "un hábil juego de uñas y yemas de los dedos en el sexo de la muchacha” (p. 55). Por último, en la tercera nota, se evoca de forma exacta el recuerdo de la anatomía del pene de Frank, que funciona como metonimia del coito, y donde Gladys consigue el "orgasmo pleno por primera vez en su vida” (Puig, 1973, p. 54) Será entonces por medio de la puesta en serie en el ámbito de las notas al pie de esa selección de escenas fragmentarias, que focalizan en las genitalidades y el coito, el espacio donde Puig construirá una síntesis del aprendizaje sexual del personaje que es puesto al servicio de la autosatisfacción. Cabe destacar, además, que, si bien las notas están intercaladas con recuerdos y evocaciones del capítulo 4, dialogan y completan su significación al referir a otras secciones de la novela. De esta forma, se quiebra la relación estricta entre el arriba y el abajo, abriéndose a un fluir de significaciones menos codificado que resuenan en el resto del libro.

En lo que refiere al aborto, a diferencia del caso anterior, las notas que Puig escribió (y que pueden encontrarse en las primeras cuatro versiones del capítulo 9) tenían por objeto conformar una biografía sentimental, artística y sexual de MEV. La idea de incluir una serie de textos sobre la vida del personaje ya 
estaba prevista en uno de los manuscritos pre-redaccionales, donde ese relato de vida se organizaba por medio de una sucesión de catorce puntos. ${ }^{11}$

Esos catorce puntos señalados se plasmarán en una serie de notas al pie que Puig desarrollará en la primera fase redaccional del capítulo. La vida de MEV se astilla en notas fragmentarias que se constituyen como un bajo continuo, vinculándose con las declaraciones del personaje a lo largo de su conversación con Leo. En las sucesivas versiones de este capítulo, Puig vacila en cómo desplegar un sistema de referencias eficaz que ponga en relación las notas al pie con el diálogo mantenido por los personajes en el cuerpo principal. ${ }^{12} \mathrm{El}$ contenido de los episodios en las notas biográficas versa, al igual que en los capítulos sobre Gladys y Leo, acerca de cuestiones de la vida sexual de MEV (su iniciación, sus amoríos, sus fantasías y deseos eróticos) En función de la lectura que aquí pretendemos ofrecer, nos centraremos en las notas numeradas como 5 y 7 , donde la narración menciona los dos abortos practicados a MEV y cómo se insertan referencialmente en el marco de la conversación con Leo. Veamos el primero de los ejemplos:

\section{LD: Tus declaraciones me parecieron más bien totalmente reaccionarias. \\ MEV: Yo lo siento así, así, si así, porque sí, siempre. Estoy contra łos anticenceptives el aborto porque creo en Dios, y en la voluntad de Dios tiene que ser obedecida. Y soy antidivorcista porque el divorcio es la prostitución de la sociedad. Se necesita Hace falta un orden, de instituciones que rijan la conducta en cuanto conducta-gula, si no es el caos (5) (TBAA, ID puig.NTbaa.N.C.58.0815).}

En esta parte de la conversación deben señalarse algunos desplazamientos verdaderamente significativos. El primer elemento a considerar es el progresivo cambio de la valoración de Leo respecto de las declaraciones que MEV ofreció a una revista. Por medio de una serie de correcciones y reescrituras, Puig construye la disconformidad del personaje en torno a los dichos públicos de ella. En una primera instancia, opta por el sintagma "un poco", al que descarta incluso antes de terminar de escribirlo, para reemplazarlo por la expresión "más bien", que introduce un matiz o corrección respecto de las declaraciones de MEV. Sin embargo, en un tercer momento decide reemplazarlo por el adverbio modal "totalmente", cuya fuerte carga semántica apunta a impugnar las opiniones de su interlocutora. Asimismo, si se presta atención a la respuesta de MEV, también en las reescrituras de sus dichos, Puig decide cambiar el tono de la discusión, al inscribir la presencia del aborto. El reemplazo de la opinión adversa de MEV respecto de los anticonceptivos por su negativa categórica frente al aborto, supone la incorporación en la novela de un debate más álgido que reclama reajustes en el tono del intercambio mantenido entre ambos personajes. La génesis de estos parlamentos, donde se evidencia la vacilación en los sustantivos y adverbios presentes en la reescritura, constituye una muestra del efecto de radicalización de las posiciones de los personajes, que Puig desarrolla en las sucesivas campañas de escritura. Asimismo, la serie que inscribe al aborto en la narración se completa con la inclusión de la nota al pie que plantea el vínculo biográfico de MEV con el tema, modificando, a los ojos del lector, las implicancias de sus declaraciones: 


\section{(5) Con algunas compañeras empezó a frecuentarba un bar cercano -no el de los estudiantes de letras, pues allí concurría la compañera por cuyo novio había sido desflorada-, donde conoció a un pintor de 35 años, de quien pronto a saber que él estaba enamorado de una pintora del grupo. El jombrado cultivaba la pintura abstracta e inició a MEV en una cultura plástica. Al año siguiente MEV tuvo su primer aborto, pagado por ella misma, debido a la falta de fondos del amigo. (TBAA, ID puig.NTbaa.N.C.57.0798).}

La lectura conjunta de ambas secciones del capítulo marca el efecto que se produce entre la justificación de MEV acerca de su oposición al aborto en el texto principal y el relato efectivo de él presente en las notas. La aparición en el cuerpo del texto de un discurso ordenador, que pone a Dios como garantía y justificación de los actos humanos, subsume al aborto presente en la nota al pie a un acto regido por una moral que lo coloca, en tanto acontecimiento, en la soledad del silencio. La contradicción que se advierte entre el texto y la nota, entre el discurso público y la experiencia vital íntima, inscribe al aborto en la corporalidad silenciosa del personaje y señala la hipocresía de una doble moral conservadora.

La segunda nota donde se menciona el aborto, aparece como un comentario subordinado al momento de la conversación, en la que Leo parece animarse a confesarle a MEV el supuesto crimen del baldío: "Una vez hice una cosa terrible" (TBAA, ID puig.NTbaa.N.C.57.0794) a lo que ella responde "MEV: Todos hemos hecho algo horrible alguna vez(7)" (TBAA, ID puig.NTbaa.N.C.57.0794). La nota que refiere a este parlamento introduce el relato alrededor de un segundo aborto:

(7) MEV abandonó la Facultad y tomó clases de pintura, En parte porque Todos sus amigos pertenecían al ambiente plástico, con la excepción de un joven que había conocido en la Facultad. El joven siempre había sentido atracción por MEV y cuando la muchacha le pidió desesperada dinero para un segundo aborto - [el] padre era en vecino casado de su edificio de departamentos otro estudiante con quien ya había terminado corta relación la ayudó sin titubear. Pocos meses después se easaren casó con él, no sin antes advertirle $\mathrm{AEV}$ Su falta de entusiasmo. (TBAA, ID puig.NTbaa.N.C.57.0798)

Resulta llamativo el uso de la palabra "horrible" que entra en diálogo con los acontecimientos que se narran en la nota al pie. Si bien ese adjetivo podría, en primera instancia, leerse en relación con las posiciones de MEV a propósito del aborto antes referidas, una segunda lectura podría sugerir otra posibilidad al respecto. En el proceso de escritura, Puig califica de "desesperado" el pedido de dinero que realiza MEV a su amigo para poder costear su segundo aborto. Este añadido, a diferencia de la nota antes analizada, le imprime un tono de dramatismo al hecho que es puesto en serie con el casamiento entre MEV y su financista. Cabe destacar que, en una primera campaña de escritura, el casamiento no aparecía connotado negativamente, mientras que, en la reescritura posterior, deliberadamente se aclara que no está fundado en un interés, sea de orden sexual o amoroso, por parte de ella, sino que es vivido como la respuesta a una deuda económica y moral contraída entre MEV y su compañero.

En ese sentido, este segundo aborto que aparece como deuda en términos económicos, marca una diferencia respecto del primero. Si MEV ya no tiene recursos propios para afrontarlo, el dinero aportado por el compañero reclama, por el uso que se hizo de él, un casamiento no deseado como forma de pago, como 
una incómoda resolución que actúa como contrapartida de la transacción. Esto supone entonces que aquello que se califica de "horrible" en el diálogo del texto principal, parecería estar más vinculado al costo personal asumido por MEV, que al aborto que lo originó. Es en este punto, y a la luz del relato de la nota, donde el tono que Puig le imprime a este parlamento de MEV, lejos de un ímpetu adoctrinador, se reviste de una tristeza abrumadora en la que subyacen las contradicciones sobre las que se edifica el discurso conservador que el personaje pretende sostener.

En la versión publicada ninguno de estos fragmentos aparece. El borramiento que Puig lleva adelante, tanto de la voz de MEV como de las notas biográficas en las últimas versiones del capítulo, si bien demandan, como hemos mencionado en el apartado anterior, por parte del lector mayores destrezas para inferir lo que no aparece narrado en la novela, plantean también de qué forma aquello que fue tachado u omitido persiste como huella en lo que el escritor decidió conservar. El efecto que Puig obtiene al ejercer el borramiento de la voz y de la "vida" de MEV en la versión final, redimensiona el vínculo del personaje con el aborto. La reescritura del parlamento de Leo presente en la versión 3, retoma las declaraciones de MEV alrededor de los temas que ya estaban presentes en el parlamento quitado:

\section{LD: Me parecieron totalmente reaccionarias. ¿Cómo a esta altura de las cosas vas a dudar sobre el divorcio y el aborto? No entiendo..." (TBAA, ID puig.NTbaa.N.C.59.0833).}

Si el lector ya no puede acceder a las declaraciones y experiencias concretas de MEV, la impugnación de Leo que aparece explicitada en la reescritura de su parlamento, ahora unilateral, reposiciona las resonancias que el aborto tiene dentro de la trama de la novela. En esta versión, el lector lo infiere por la afirmación de Leo, el tema también se inscribe en los dichos que MEV realizó públicamente ante un periodista, pero con un sentido diferente. Sin su voz, sin las notas que reponen la experiencia en primera persona, la cuestión del aborto queda reducida a un tema de agenda pública, en tanto una opinión general acerca de una cuestión de actualidad presente en los discursos periodísticos de la época, pero no inscripto en la propia experiencia del personaje.

En novela siguiente, El beso de la mujer araña, Puig vuelve a utilizar el recurso de las notas al pie. A diferencia de las que se incluyen en la novela anterior, las nueve notas presentes en el texto (ocho sobre aspectos teóricos acerca de la homosexualidad y una referida a un argumento cinematográfico) han sido largamente analizadas por la crítica. En su indispensable trabajo sobre el proceso de génesis de las notas en cuestión, Daniel Balderston analiza las fuentes empleadas por Puig y postula que "las notas configuran un breve tratado sobre la sexualidad, que enfoca sobre todo la relación entre liberación sexual y cambio social en general" y concluye "ese tratado merece leerse como tal, y en su totalidad, no apenas en contrapunto a la 'acción principal'” (2002, p. 564). Si bien coincidimos con la afirmación de la autonomía narrativa que presenta el contenido discursivo de las notas, advertimos que no pueden ser leídas fuera del contexto en el que el autor las inscribió. Se trata de notas que refieren y dialogan con las voces de Molina y Valentín y, si asumimos que ese conjunto de paratextos desplegados a lo largo del libro, constituyen un texto uniforme que se segmenta en "partes" o "entregas", la irrupción de la primera nota que conformaría ese tratado, actúa como una respuesta directa al pedido que enuncia Valentín: "Si estamos en esta celda juntos mejor es que nos comprendamos, y yo de gente de tus inclinaciones sé muy poco” (Puig, 2005 [1976], p. 56). De este modo, las notas al pie vienen a responder esa demanda y en ese sentido, aunque la naturaleza discursiva que articula las notas difiera del uso llevado adelante por Puig en la novela anterior, el efecto que produce la superposición del arriba y el abajo habilita señalamientos que modifican la percepción de los hechos narrados en el texto principal, ${ }^{13}$ es decir que allí se explica algo que permite entender la configuración subjetiva de los personajes.

Si en The Buenos Aires Affair la nota al pie exploraba la sexualidad femenina, en El beso de la mujer araña la mujer es reemplazada por el homosexual. Fue Roberto Echavarren quien advirtió continuidades notables entre Gladys y Molina a partir de fantasías recurrentes, donde ambas sueñan con ser: "un ama de casa con un marido guapo y enamorado" (2002, p. 457). A la vez, estas ensoñaciones se constituyen como una Ilusión compensatoria respecto de la realidad efectiva de ambos personajes, marcando la deliberada configuración 
de Molina como una mujer rara, ${ }^{14}$ inscripto en una serie que se inaugura con la mujer pantera, al comienzo de la novela, y que cierra el libro con la mujer araña. En diversas entrevistas realizadas por activistas de los grupos de liberación gay, Puig fue interrogado acerca de la fijación femenina con la que construyó al personaje de Molina. Dirá a los militantes gays brasileños: "escribí esta novela porque necesitaba un personaje que defendiera el papel de la mujer sometida.” (Puig, 2020). Molina encarna, como Puig lo designa en sus notas y apuntes pre-redaccionales, una folle, es decir una loca. La subjetividad femenina exagerada en figura del homosexual se constituye como la radicalización misma del imaginario femenino. Pero si las notas al pie refieren sobre la homosexualidad, construyendo un discurso que se pretende distante, objetivo y que apunta producir un efecto generalizador por medio de la superposición de teorías y auctoritates, es en el diálogo efectivo con las experiencias y la subjetividad homosexual femenina encarnada en Molina, donde la novela abandona la pretensión universalizadora, al recortarse en un caso concreto, donde la nota al pie reduce su alcance a un tipo particular de homosexualidad fijada en lo femenino.

$\mathrm{Al}$ igual que en The Buenos Aires Affair, Puig retomará la cuestión del aborto, aunque esta vez no lo incluirá en las notas al pie, sino en el texto principal y con un matiz diferente. En los años en los que Puig está escribiendo esta novela, ya exiliado en México, entablará amistad con Elena Urrutia, una de las feministas mexicanas más importantes. ${ }^{15}$ En 1975 Urrutia publicó una compilación de una serie de conferencias realizadas tres años antes en el volumen titulado Imagen y realidad de la mujer, donde se ofrece un pormenorizado balance de los debates feministas de la época. La aparición de este libro es contemporánea a la escritura de El beso de la mujer araña y coincide con el momento de mayor proximidad de Puig con un sector del feminismo mexicano. De los textos allí compilados resulta interesante detenerse en algunas ideas que articulan la evaluación de la libertad sexual y de la reivindicación del derecho al aborto, incluidas en el texto de Alaíde Foppa. En su trabajo "Feminismo y liberación" sostiene que el advenimiento de la píldora volvió a la mujer dueña de su capacidad reproductiva, pero señala la creciente defensa entre los grupos de liberación femenina del derecho al aborto: "al exigir la legalización del aborto - o dicho a la inversa, la no delictuosidad del aborto-, defienden la libertad de la mujer para decidir ella misma si quiere o no traer un hijo al mundo. (Y reconocen al mismo tiempo la triste realidad de los millones de abortos que se realizan en el mundo clandestinamente" (Foppa, 1975, p. 95).

El eco de estos debates puede encontrarse en la construcción imaginaria que rodea a la figura de la compañera de Valentín, "Jane Randolph" que: "Siempre fue revolucionaria (...) le dio por la revolución sexual” (Puig, 2005 [1976], p. 43). En la imagen que de ella ofrece Valentín por medio del relato, se inscribe la presencia del aborto como una deliberada toma de posición política frente a los esquemas y mandatos hegemónicos:

Jane no quería repetir ningún esquema viejo, y tenía desconfianza.

- ¿Abortos?

-Sí, uno. Eso la afianzó más en vez de deprimirla. Vio claro que si tenía un hijo ella misma no iba a poder madurar, no iba a poder seguir una evolución. Su libertad iba a quedar limitada (Puig, 2005 [1976], p. 94).

Ahora, cabría preguntarse: ¿Qué opera en el desplazamiento de una novela a la otra alrededor del aborto? ¿Qué concepciones trasmiten los personajes a propósito de la libertad de la sexualidad femenina? Más precisamente en qué se funda la diferencia entre los imaginarios alrededor del aborto que se desprenden de MEV y "Jane Randolph". Lo que pone de manifiesto la distancia en sus divergentes concepciones alrededor del aborto, está fundada en salto generacional ${ }^{16}$ que introduce la irrupción de nuevos imaginarios sexuales experimentados por las mujeres en la segunda mitad del siglo XX. Como sostiene Valeria Manzano: "entre fines de los años cincuenta y principios de los años sesenta, las experiencias y las expectativas de las jóvenes comenzaron a diferir notablemente de las que habían vivido y abrigado las mujeres de generaciones anteriores" (2017, p. 157). 
De esta manera, MEV y “Jane” encarnan, en la narrativa de Puig, esa distancia epocal que se traduce en dos momentos diferenciados y que expresan dos concepciones divergentes alrededor de la sexualidad femenina. La mirada que domina el imaginario conservador de MEV en relación con el aborto, se corresponde a un momento anterior y se contrapone con el derecho de elegir de "Jane" inscripta en el contexto de la revolución sexual que se da en los años sesenta (Galeotti, 2003; Cosse, 2016). El aborto, circunscripto en The Buenos Aires Affair en las notas al pie y connotado negativamente por MEV, se desplaza hacia el cuerpo principal del texto en El beso de la mujer araña, marcando el cambio subjetivo alrededor del tema. Asimismo, el trayecto que va de una novela a otra, de las notas al pie al cuerpo del texto, permite advertir que la sexualidad femenina no estaba al margen, sino que está resguardada en el margen, manteniéndose a salvo y esperando condiciones más propicias para liberarse.

\section{CODA: EL ARCHIVO VIVO}

La lectura que hemos ofrecido de los manuscritos de Tb Buenos Aires Affair, a través de la indagación de algunos aspectos neurálgicos de su proceso escritural permitió iluminar, por medio de un análisis detallado del uso de los diálogos, de la voz narrativa y de la emergencia de las notas al pie, la escritura de esta tercera novela como una instancia que se constituye un punto de inflexión dentro del régimen de escritura ficcional de Manuel Puig. Desnudar los procesos de esa escritura, como se ha hecho en las páginas precedentes, a la luz de las diferentes estrategias de manipulación y experimentación, como así también por medio de la incorporación de temas y discursos aludidos, supone repensar qué es lo que a partir de allí cambia y cómo vislumbrar, por medio de esas vacilaciones, correcciones y dudas, la obra por venir. Leer por primera vez, el caudaloso material escritural de The Buenos Aires Affair inaugura la posibilidad de comprender qué, de lo que se encuentra inscripto en la materialidad de los originales conservados, contiene germinalmente aquello que se desarrollará, de diversas formas, en las tres novelas siguientes. Puig, con la convicción de un proyecto literario que se rehúsa al facilismo del éxito probado y que asume nuevos riesgos de escritura, incorpora las reflexiones sofisticadas de la teoría, la agenda de los debates políticos y sexuales, fundando en esos añosetenta, una obra atravesada intensamente por los desafíos y debates de su presente.

Asimismo, la lectura desde el archivo supone desmontar algunas concepciones y prejuicios todavía vigentes. En esa misma década, Puig vivió en cuatro países y realizó numerosos viajes, pero eso no impidió que construyera un archivo de su escritura que, contrariamente a lo que se cree, se rehusaba a sucumbir a la fantasía de conservarlo todo. La exploración del archivo Puig no admite una concepción fetichista y tranquilizadora que pretende reducir a esos originales de escritura a un mero acto de vanidad. Las huellas del impulso creativo que perviven en esos papeles conservados no pueden pensarse a partir de un textualismo ingenuo que venera al archivo como una piedra funeraria, sino que reclama la certeza de una lectura crítica que advierta que, en el gesto de Puig, había una conciencia del archivo, una porción viva y latente de su propia producción. El archivo, no como un espacio fosilizado y burocratizado, regido por las reglas y convenciones de orden institucional, sino como un reservorio que habilita lecturas más complejas y sutiles, que permiten diseñar constelaciones que pretenden dar cuenta de las diferentes huellas de un trabajo en proceso, al que Puig acudía cada vez que se presentaba la angustia de la página en blanco o que su memoria prodigiosa, decidía volver a cosechar esas semillas de escritura cuidadosamente plantadas y atesoradas entre los papeles viejos.

\section{ReFERENCIAS}

Aguilar Mora, J. (1973). Manuel Puig. ¿Dónde están los enigmas? The Buenos Affair. Siempre (6), 1-5.

Amícola, J. (2000). The Buenos Aires Affair: novela policial. En Camp y posvanguardia. Manifestaciones culturales de un siglo fenecido. Buenos Aires, Argentina: Paidós. 
Balderston, D. (2002). Sexualidad y revolución: en torno a las notas de El beso de la mujer araña. En J. Amícola y J. Panesi (coords.), Manuel Puig, El beso de la mujer araña. Edición crítica. Madrid, España: ALLCA XX, 564-574.

Bardauil, P. (1998). Literatura y revolución: la recepción de Puig en las revistas Los Libros y Crisis, en J. Amícola y G. Speranza (comps.), Encuentro Internacional Manuel Puig, Rosario, Argentina: Beatriz Viterbo, 95-103.

Barthes, R. (2005). La preparación de la novela. Notas de cursos y seminarios en el Collège de France, 1978-1978 y 1979-1980. Buenos Aires, Argentina: Siglo XXI.

Barthes, R. (1988). Análisis estructural del relato. México D.F., México: Premiá.

Benstock, S. (1983). At the Margins of Discourse: Footnotes in the Fictional Texts. PMLA, 98 (2), 204-225.

Cabrera, D. (2016). Las lenguas vivas. Zonas de exilio y traducción en Manuel Puig. Buenos Aires, Argentina: Prometeo.

Corbatta, J. (2009). Manuel Puig. Mito personal, historia y ficción. Buenos Aires, Argentina: Corregidor.

Cosse, I. (2010). Pareja, sexualidad y familia en los años setenta. Una revolución discreta en Buenos Aires. Buenos Aires, Argentina: Siglo XXI.

Debussy, P. (2017). The Buenos Aires Affair y un montaje criminal. Violencia, política y poder. Badebec, 7 (13). Recuperado de https://revista.badebec.org/index.php/badebec/article/view/22

Echavarren, R. (2002). Género y géneros, En J. Amícola y J. Panesi (Coords.), Manuel Puig, El beso de la mujer araña. Edición crítica. Madrid: ALLCA XX, 456-462.

Foppa. A. (1975). Feminismo y liberación. En E. Urrutia (comp.) Imagen y realidad de la mujer. México D.F., México: SepSetentas.

Galeotti, G. (2003). Historia del aborto. Los muchos protagonistas e intereses de una larga vicisitud. Buenos Aires, Argentina: Nueva Visión.

García Ramos, J. M. (1991). Manuel Puig. Semana de Autor sobre Manuel Puig realizada del 24 al 27 de abril de 1990 en el Instituto de Cooperación Iberoamericana. Madrid, España: Ediciones de Cultura Hispánica.

Giordano, A. (2001). Manuel Puig. La conversación infinita. Rosario, Argentina: Beatriz Viterbo.

Goldchluk, G. (2020). Manuel Puig: una frívola mujer despreocupada de la suerte de su pueblo. Jornada virtual Manuel Puig. Recuperado de https://www.youtube.com/watch?v=s_9dwKiO4EE\&t=543s.

Goldchluk, G. (2016). El archivo como política de lectura: aportes de la crítica genética. En Karina Janello y Marcela Frías(comps), Actas Primeras Jornadas de reflexión sobre la construcción del archivo (52-64).Buenos Aires, Argentina: CEDINCI-UNSAM.

Goldchluk, G. (2003). Intertextualidad y génesis en los textos mexicanos de Manuel Puig: Novelas, guiones, comedias musicales (1974-1978) (Tesis doctoral). Recuperado de http://www.memoria.fahce.unlp.edu.ar/tesis/te.157/t e.157.pdf

Grafton, A. (1998). Los orígenes trágicos de la erudición. Breve tratado sobre la nota a pie de página. Buenos Aires, Argentina: Fondo de Cultura Económica.

Hay, L. (1994). La escritura viva. Filologia, XXXVII, 5-22.

Heker, L. (1974). Sobre The Buenos Aires Affair. El Escarabajo de oro, (47), 19.

Jill-Levine, S. (2002). Manuel Puigy la mujer araña. Su vida y ficciones. Buenos Aires, Argentina: Seix Barral.

Manzano, V. (2017). La era de la juventud en Argentina. Cultura, politica y sexualidad desde Perón hasta Videla. Buenos Aires, Argentina: Fondo de Cultura Económica.

Martinetto, V. (2016). The Buenos Aires Affair: anatomia di una censura. Manuel Puig reloaded, Roma, Italia: Edizioni Fili d'Aquilone, 9-30.

Páez, R. (1995). Manuel Puig. Del pop a la extrañeza. Buenos Aires, Argentina: Almagesto

Puig, M. (2020). Manuel Puig habla de casi todo. Transas. Letras y artes de América Latina.8 (13). Recuperado de ht tps://www.revistatransas.com/2020/08/13/puig-en-rio/.

Puig, M. (2005 [1976]). El beso de la mujer araña. Buenos Aires, Argentina: Planeta.

Puig, M. (1985). La cara del villano. Recuerdo de Tijuana. Barcelona, España: Seix Barral.

Puig, M. (1980). Maldición eterna a quien lea estas páginas. Barcelona, España: Seix Barral. 
Puig, M. (1979). Pubis angelical. Barcelona, España: Seix Barral.

Puig M. (1973). The Buenos Aires Affair. Novela policial. Buenos Aires, Argentina: Sudamericana.

Rodas, G. (2015). Edición critico-genética de Boquitas pintadas. Folletín. (Tesis doctoral).Universidad Nacional de La Plata, Facultad de Humanidades, La Plata.

Romero, J. (2002). Los posibles narrativos. Estudio crítico genético de la fase prerredaccional. En J. Amícola y J. Panesi (coords.), Manuel Puig, El beso de la mujer araña. Edición crítica. Madrid, España: ALLCA XX, XXXIV-LIII.

Romero, J. (1996). Del monólogo al estallido de la voz. En J. Amícola (comp.) Materiales iniciales para La Traición de Rita Hayworth. Buenos Aires, Argentina: Universidad Nacional de La Plata, Facultad de Humanidades y Ciencias de la Educción, Centro de Estudios de Teoría y Crítica Literaria.

Rosenkrantz, G. (1999).El cuerpo indómito. Espacios del exilio en la literatura de Manuel Puig. Buenos Aires, Argentina: Simurg.

Sarlo, B. (1974). Sábato, Cortázar, Puig: ¿parodia o reportaje?. Los Libros, (36), 32-33.

Speranza, G. (2000). Manuel Puig: después del fin de la literatura. Buenos Aires, Argentina: Norma.

\section{Notas}

* Este artículo se inscribe en una investigación en curso financiada por una beca doctoral de la Universidad de Buenos Aires, en el marco del proyecto UBACyT (20020130200191BA) "Pasando revista”, dirigido por la Dra. Sylvia Saítta y radicado en el Programa de Historia Social y Económica (PEHESA) del Instituto de Historia Argentina y Americana "Dr. Emilio Ravignani" (UBA-CONICET).

1 Las citas corresponden a una carta inédita conservada en el archivo familiar.

2 Tanto la revista Los Libros como El Escarabajo de Oro fueron lapidaros en sus lecturas. Liliana Heker dirá: "por rendir tributo a la cursilería, estatiza nuestro mundo; lo fija en una caricatura. Transforma un conflicto en un pasatiempo." (1974, p. 19) Por su parte, Beatriz Sarlo sostendrá "Fracasado el artificio, desaparece el relato, se revela la inutilidad y la inconsistencia de lo narrado" (1974, p. 33). En palabras de Pablo Bardauil: "en consonancia con una repercusión menor por parte del público, los antiguos elogios críticos devinieron o bien en llamativo silencio o bien en desembozada acusación" (1998, p. 95).

3 Si atendemos a clasificaciones No pertenece a la saga pueblerina de Coronel Vallejos (Corbatta, 1988) menos aún en las clasificaciones que organizan la obra alrededor del exilio (Rosenkrantz, 1999; Goldchluk, 2005).

4 Para una reflexión actualizada acerca de este debate, veáse el trabajo de Pablo Debussy (2018).

5 Todas las citas de manuscritos corresponden a ARCAS, se indica el nombre que tiene el documento en el archivo digital y, a continuación, se coloca el código de identificación digital.

6 Las diferentes versiones de estos capítulos pueden consultarse en ARCAS. Para comprender el complejo proceso escritural que subyace a la primera novela de Puig habrá que esperar al exhaustivo trabajo que viene desarrollando Lea Hafter, que tiene por objetivo la edición crítico-genética de esta novela, deslindando una primera formulación que Puig tituló El desencuentro y el proceso de reescritura que luego llevó a La traición de Rita Hayworth.

7 Puig era un lector dedicado de la obra de Barthes. En su biblioteca personal constan dos ejemplares de su producción: Sade, Loyola y Fourier en la traducción de Monte Ávila de 1977 y Fragments d'un discours amoreaux en la edición francesa del mismo año. Puig solía leer en bibliotecas de modo que es probable que haya consultado este texto en alguna biblioteca pública o en casa de algún amigo mientras escribía The Buenos Aires Affair. El escritor y el crítico francés se conocieron en París en 1969 a instancias de Severo Sarduy. Alberto Manguel, testigo del encuentro, lo relata de esta manera: "Recuerdo una reunión en el [Café de] Flor con Sarduy, Barthes y Manuel. Sarduy lo conocía por medio de François Wahl. Recuerdo que en ese encuentro Barthes mencionó a Julia Kristeva, y entonces Puig dijo 'Es un pseudónimo de Julie Christie'. A mí me pareció graciosísimo, pero Barthes no se rio. No sé si fue porque no entendió el chiste o porque le pareció absurdo" [Entrevista con Alberto Manguel, 22 de marzo de 2020]

8 En los pre-redaccionales de El beso de la mujer araña esa experimentación barthesiana continúa. Puig se propone usar distintos narradores y técnicas en el plan inicial de la novela, de modo que en los borradores de su cuarta novela se mantiene ese espíritu. Para un análisis pormenorizado de esta cuestión véase (Romero, 2002). Dirá el propio Puig al respecto: "El proyecto inicial de El beso de la mujer araña no preveía ese predominio del diálogo e iba a ser contado, en parte, con diálogo y otros sectores de la trama con diferentes técnicas. (...) Tenía prevista una cantidad de recursos técnicos, pero, el primero, iba a ser el diálogo y deseché todo lo otro. (García Ramos, 1991, p. 69). Durante su estadía en México, Puig destruye la primera versión de la novela, no quedando rastros de esa primera fase redaccional. 
9 A efectos de señalar algunas estrategias de reescritura de los diálogos, nos interesa plantear dos ejemplos concretos que permiten advertir el modo en el que Puig interviene sobre esa forma narrativa, para producir un efecto de indeterminación en la trama de la novela. En el capítulo 14 la primera versión se encontraba enmarcada en el diálogo entre Leo y su psicoanalista. En la versión publicada, en cambio, la narración cambia el punto de vista al recrear esa escena desde la perspectiva del portero asentada en una declaración. El segundo ejemplo se vincula con las reescrituras del capítulo 10, que retoma la conversación entre MEV y el oficial de policía. Allí también opera un desplazamiento entre la formulación inicial, donde el diálogo aparece desarrollado, y una relectura posterior en la que Puig reescribe el texto. La conversación entre ambos personajes, al igual que en la edición publicada, aparece en la novela mediada por la cinta magnetofónica. No obstante, en la segunda campaña de escritura, Puig reformula su realización, al prescindir de la máquina y al emplear una nueva forma de registro de esa oralidad. En la acotación de la escena, se alude al desperfecto de la máquina y se introduce una nueva forma para el registro de esa voz: "abre un cuaderno y empuña la lapicera para tomar nota taquigráfica" (Puig 1973, p. 175). La incorporación de la técnica taquigráfica, que supone el registro escrito de la voz mediado por símbolos, traslada la captura la voz, por medio de un código convencional fundado en la escritura.

10 El uso de la nota al pie es un recurso constante en la literatura argentina con diferentes entonaciones y significaciones. Por nombrar algunos casos, la nota al pie puede encontrarse en novelas como Amalia (1855) de José Mármol, pasando por el ciclo de Los siete locos/Los lanzallamas (1929-1931) de Roberto Arlt. También su uso es recurrente en los relatos de Jorge Luis Borges o en La invención de Morel (1940) de Adolfo Bioy Casares llegando, por último, al emblemático cuento "Nota al pie" (1967) de Rodolfo Walsh.

11 En el manuscrito pre-redaccional de The Buenos Aires Affair (ID puig.NTbaa.N.C.12.0135R) ya estaba presente el diseño de la biografía, pensada alrededor de catorce notas, segmentadas espacialmente en los ámbitos en los que MEV mantiene sus conversaciones con Leo (la oficina, el bar y el departamento).

12 Mientras que, en las dos primeras versiones redaccionales, las notas se listan al final (sea por medio de números o de letras), en la versión 3 decide intervenir el dactiloescrito obturando los parlamentos de MEV, pero manteniendo las notas. Ya en las dos versiones siguientes, el capítulo prescinde de toda alusión al personaje femenino, centrando su principal atención en la reescritura de las intervenciones de su interlocutor.

13 Sobre esta cuestión en particular, remitimos a los trabajos de Roxana Páez (1995) y de Julia Romero (1996).

14 Sobre las diversas formulaciones del concepto de mujer rara en la obra de Puig, véase el trabajo de Graciela Goldchluk (2020).

15 La amistad de Puig con Elena Urrutia contribuyó a afianzar el contacto del escritor con algunos de los debates que gravitaron, tanto sobre su cuarta novela, como así también sobre Pubis angelical, donde de nuevo se plantea una tensión entre mujeres sumisas y conservadoras como Ana, frente a las ideas feministas expresadas por su amiga mexicana, Silvia.

16 En las notas biográficas presentes en las primeras redacciones de The Buenos Aires Affair no se especifica a qué edades MEV se practicó los abortos, pero por las vivencias narradas, se podría llegar a inferir que fue durante su juventud. $\mathrm{Si}$ nos atenemos a las cronologías que proponen las novelas se pueden concluir algunas cuestiones. En 1969 (presente de la narración) MEV tiene "casi 60 años" (Puig, 1973, p. 160). Por su parte, en 1975, año en el que está ambientada El beso de la mujer araña, "Jane Randoph" tiene "veinticuatro años" (Puig, 2005 [1976], p. 43) Si reponemos los cálculos, MEV tenía la misma edad que la compañera de Valentín en 1933. 